\title{
PID Controller optimization using Metahuristic Controller with Different Nonlinearities
}

\section{G. Sundari ${ }^{\mathrm{a}}$, and J. Shanmugapriyan ${ }^{\mathrm{b}}$}

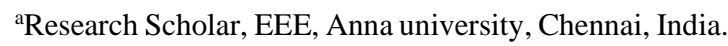

${ }^{\mathrm{b}}$ Associate professor, EEE department, Vel Tech Multi Tech Dr Rangarajan Dr Sakunthala Engineering college, Anna university, Chennai, India.

Article History: Received: 11 January 2021; Accepted: 27 February 2021; Published online: 5 April 2021

\begin{abstract}
This paper mainly explains the application of Metaherustic controller for tuning the parameter of PID controller. The minimization of error function has been done by improving the static and dynamic performances of the system like steady state error, Peak Overshoot, and Settling Time. This could be possible by means of applying metaherustic controller like GA in tuning the PID controllers under different Nonlinearities. The main intention of this paper is to support the specifications of PID controller at various Nonlinearities such as sinusoidal and saw tooth noise. The projected scheme derives the wonderful closed-loop response of second order system and then, it provides the effectiveness of the proposed method compared to the conventional methods.
\end{abstract}

Keywords: PID Controller, GAPID Controller, Conventional Controller, Sawtooth Noises, Nonlinearities

\section{Introduction}

In all systems, controller is an essential preliminary observe. Countless work has been approved by researchers and many controllers have been provided for linear and nonlinear, stable and unstable processes. Consequently, these systems produce unwanted overshoot. Previously, PID controllers with the assistance of Z-N method (Prathibanandhi, 2018; Aroulanandam, V. V., 2019) have been used to tune the controller. However, they have some limitations to get an optimal solution. Hence, the metaherustic approach such as GA has been used for tuning the PID controller parameters (Ibtissem, 2012; Shankar, 2020; Sekaran, 2020).

The DC motor drive which has the rated speed of $1000 \mathrm{rpm}, 240 \mathrm{~V}, 15 \mathrm{~A}$ has been considered for evaluation. The PID controller has been initially designed for the machine by using Z-N method (Latchoumi, 2013). Then, the performances are obtained. Later by using GA methods, PID controller has been designed and its performances are analyzed. For those controllers, different disturbances such as sinusoidal and sawtooth are given and their performances are obtained.

\section{Modelling of Separately Excited Dc motor}

DC motor includes three parts like an armature; a circuit for attractive topic supplied by magnets of poles; and a commutator. In order to build the DC automobiles switch, its easy arithmetical version has been used. Accordingly, these motors have great velocity and torque to manage.

Torque developed by the motor is given by flux and armature current (Younis, 2018; Ranjeeth, 2019).

$$
\text { Torque }=\text { Kt Ia }
$$

Back Emf is directly proportional to the change in Angular velocity

$$
\text { Back emf }=\mathrm{Kb} \mathrm{d} \theta / \mathrm{dt}
$$

Torque equation $\mathrm{d} \theta / \mathrm{dt} 2=1 / \mathrm{J}[\mathrm{Kt} \mathrm{Ia}-\mathrm{B}(\mathrm{d} \theta / \mathrm{dt})+\mathrm{Tl}]$

The differential equation of the armature circuit is

$$
\mathrm{dIa} / \mathrm{dt}=1 / \mathrm{L}[-\mathrm{R} \quad \mathrm{Ia}+\mathrm{Va}-\mathrm{Kb}(\mathrm{d} \theta / \mathrm{dt})]
$$

By using have been designed through the above two basic equations, The armature resistance, friction, force, inductance, back emf, inertia of motor the mathematical model. The following TABLE-I shows the corresponding DC motor parameters.

Table 1. DC Motor Parameters

\begin{tabular}{|l|l|}
\hline Parameters & Values \\
\hline
\end{tabular}




\begin{tabular}{|c|c|}
\hline Armature Inductance- La & $0.121 \mathrm{H}$ \\
\hline Armature Resistance -Ra & $11.2 \Omega$ \\
\hline Rotor Inertia-J & $0.02215 \mathrm{kgm} 2$ \\
\hline Armature Voltage-Va & $240 \mathrm{~V}$ \\
\hline Viscous friction constant-B & 0.002953 \\
\hline orque constant $-\mathrm{K}_{\mathrm{t}}$ & $1.28 \mathrm{Nm} / \mathrm{A}$ \\
\hline Back emf constant- $\mathrm{K}_{\mathrm{b}}$ & $1.28 \mathrm{Vs} / \mathrm{rad}$ \\
\hline Speed $-\mathrm{N}_{\text {ref }}$ & $1000 \mathrm{rpm}$ \\
\hline
\end{tabular}

\section{Conventional Controller}

The PID controllers are mostly used in controllers for speed control of Drive. The proportional, integral and derivative actions are the three main functions of the conventional controllers. The Fig.1.represents the pictorial representation of PID controller

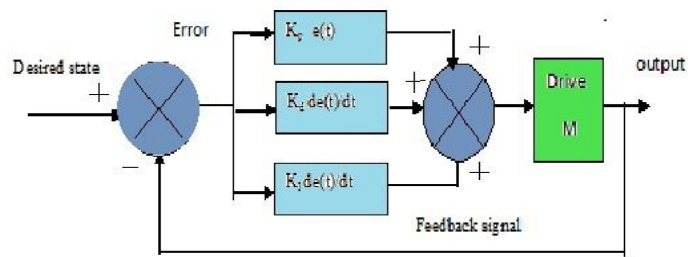

Figure 1. Pictorial Representation of PID Controller

$$
\mathrm{U}(\mathrm{t})=\mathrm{Kp}+\mathrm{Ki}\left[\int \mathrm{e}(\mathrm{t}) \mathrm{d}\right]+\mathrm{Kd}
$$

\section{Genetic Algorithm}

The convergence of this algorithm provides the association between the most excellent robustness value and the common fitness value (Umesh, 2013; Latchoumi, 2017). A simple GA is derived by using primary operators like reproduction, crossover and mutation. Here, large probabilities of Fitter chromosomes are elected. Hence, it is begun with an initial population (Prathibanandhi, 2018). The GA derives the information from the initial population; generates the new individuals by using genetic operators that can replace the content of the old information, and then from the new population, another generation is reproduced. After a number of generations, the algorithm will be on the way to the best chromosome, which represents the optimum solution or near optimal (Thirupura Sundari, 2019; Ranjeeth, 2020). This process can be visualized by Fig.2.

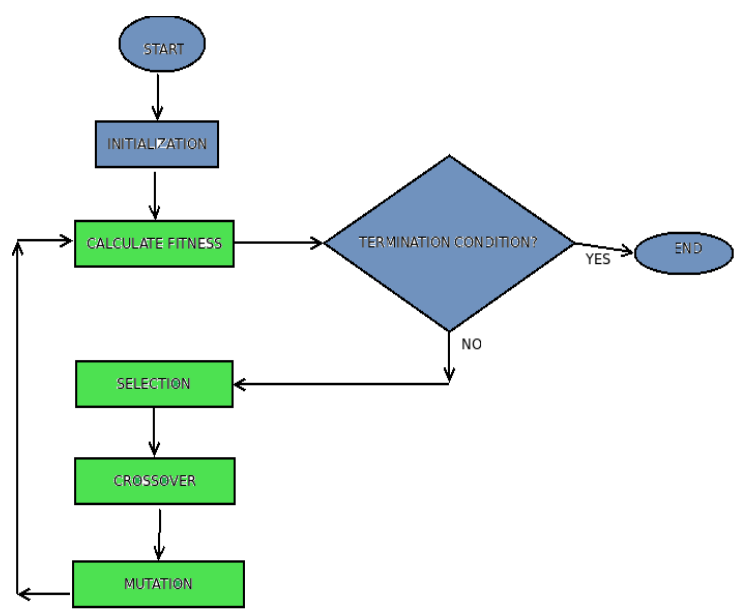

\subsection{Problem illustration}

Figure 2 Chromosome structure 
The parameters of the PID controllers can be represented as each individual population. For the speed control problem under consideration, the controller parameters are represented in binary form as follows:

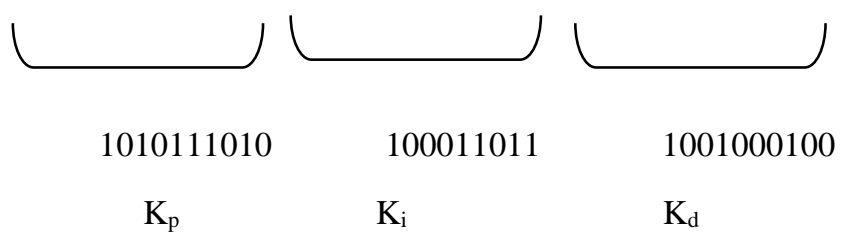

\subsection{Population Initialization}

Population Initialization is needed for any GA. The most common method is to create solutions randomly for the entire population and it is the normal method in GA (Hong-Gui , 2018). In order to control the speed of the drive under various considerations, all the individuals are initialized arbitrarily using an identical arbitrary number of binary strings (i.e) ones and zeros.

\subsection{Evaluation function}

GA finds the optimal solution by minimizing the given fitness function which gives the value of the problem solution. In the speed control, the intention is to minimize the

Integral Absolute Error (IAE) of PID controller by satisfying the constraints. Now, the new objective function becomes

$$
\operatorname{IAE}=\sum|\operatorname{Nref}(\mathrm{t})-\operatorname{Nact}(\mathrm{t})|
$$

$\mathrm{t}=0$

Here tsim $=$ simulation time

Nref $(t)=$ Desired speed of motor at any instant

Nact $(t)=$ the actual speed of motor at any instant

\subsection{Genetic Operator}

The genetic operator emphasizes good solutions and destroys the bad solutions by maintaining population constant. The objective is to permit the "fittest" individuals, on the way to be selected to reproduce. In this work, "tournament selection" is selected. Bit mutation and two point crossover are used on the selected members to get a fresh population. Thus, the Genetic algorithm approach has been implemented for tuning PID parameters to the speed control problem and the results obtained are given.

The parameter settings of GA are given in TABLE II

Table 2: GA Parameters settings

\begin{tabular}{|c|c|}
\hline Genetic Parameters & Values \\
\hline Bit number & 8 \\
\hline Rate of cross over & 0.75 \\
\hline Rate of mutation & 0.06 \\
\hline Population size & 10 \\
\hline Generations & 100 \\
\hline
\end{tabular}




\section{Simulation Results}

The PID controller of DC motor is tuned by means of Ziegler-Nichols method (Harion, 2019). The tuning results are given below. The tuning values from this algorithm are

$$
\mathrm{Kp}=0.8531 ; \mathrm{Kd}=0.0047 ; \mathrm{Ki}=38.7769
$$

After the PID controller parameters are tuned for the following Nonlinearities such as sinusoidal, Sawtooth Noises, the speed control of the DC motor has been obtained as shown in fig.3.a and fig.3.b.

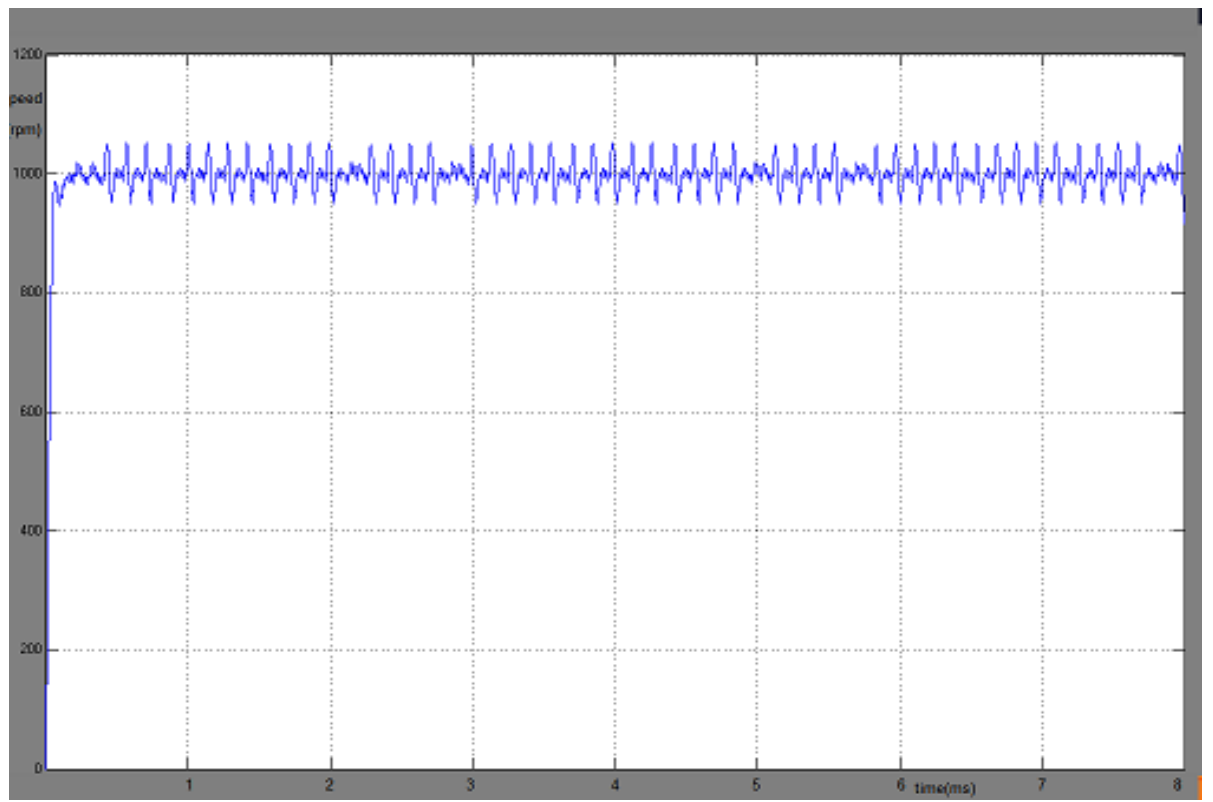

Figure 3.a.Conventional PID controller response for sinusoidal Nonlinearity(Speed of DC drive(rpm) Vsltime(ms)

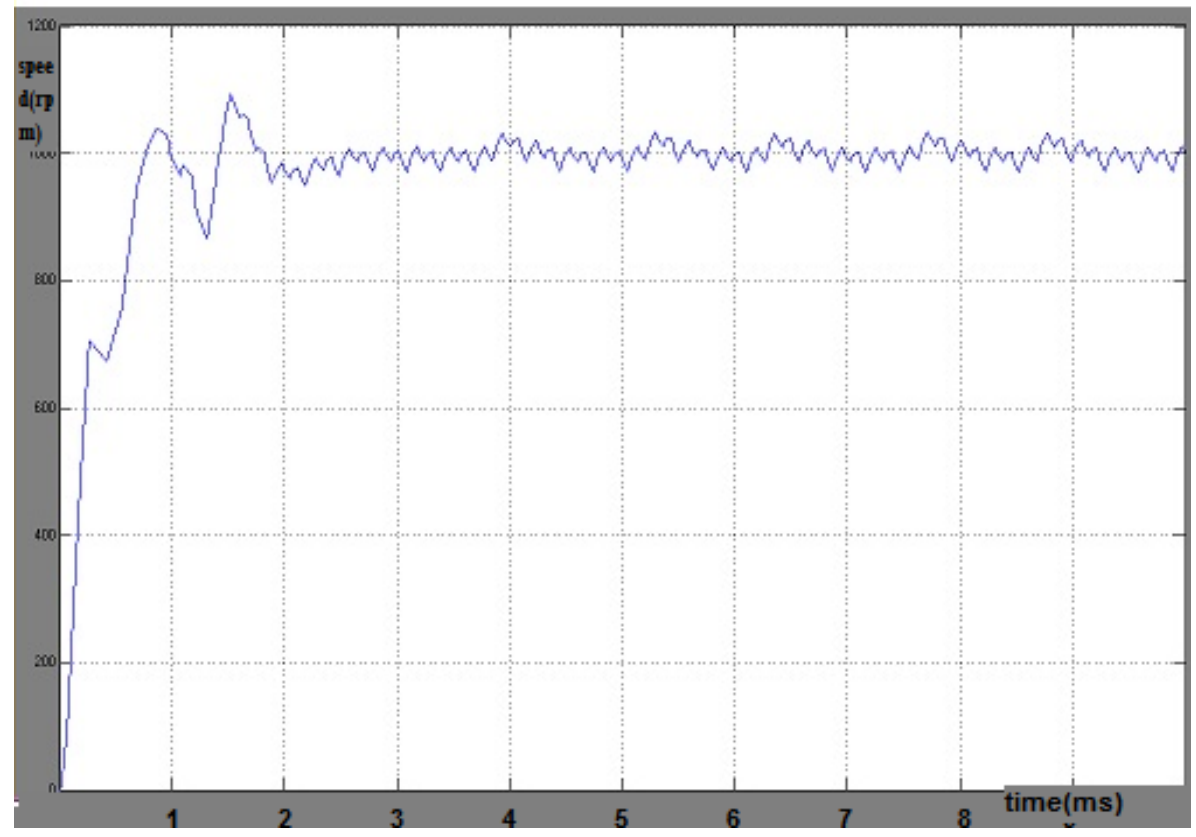

Figure.3.b.Conventional PID controller response for Saw tooth Nonlinearity(Speed of DC drive(rpm) Vsltime(ms) 
The suitability of the proposed method is demonstrated and GA based method has been applied to obtain the optimal solution. The parameter settings of GA are given in TABLE-II. These parameters are constant across all runs. The convergence of this algorithm provides the association between the most excellent robustness value and the common fitness value and the graphical representation of the simulation results is shown in fig.4. From the graph, it is very clear that after 30 generations, there is no significant reduction in the objective function value and the corresponding parameter values are the optimum parameter values of the PID controller.

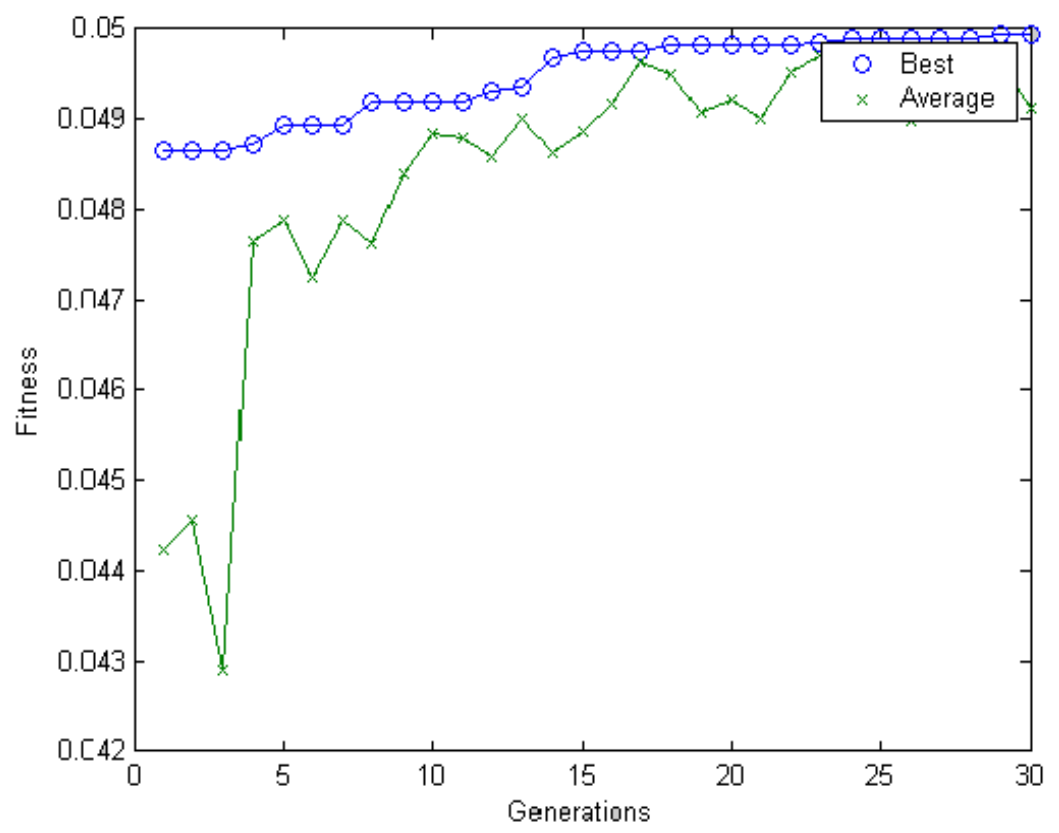

Figure.4.Convergence of GA-PID controller

The Convergences of GA-PID controller are $\mathrm{Kp}=0.8531 ; \mathrm{Kd}=0.0047 ; \mathrm{Ki}=38.7769$. The optimum $\mathrm{Kp}$, $\mathrm{Kd}, \mathrm{Ki}$ values are given to the PID controller of the simulation circuit and the speed control of the DC motor is obtained under the following circumstances as given in fig.4.a and fig.4.b.

a) At Sinusoidal Noise

b) At saw tooth noise

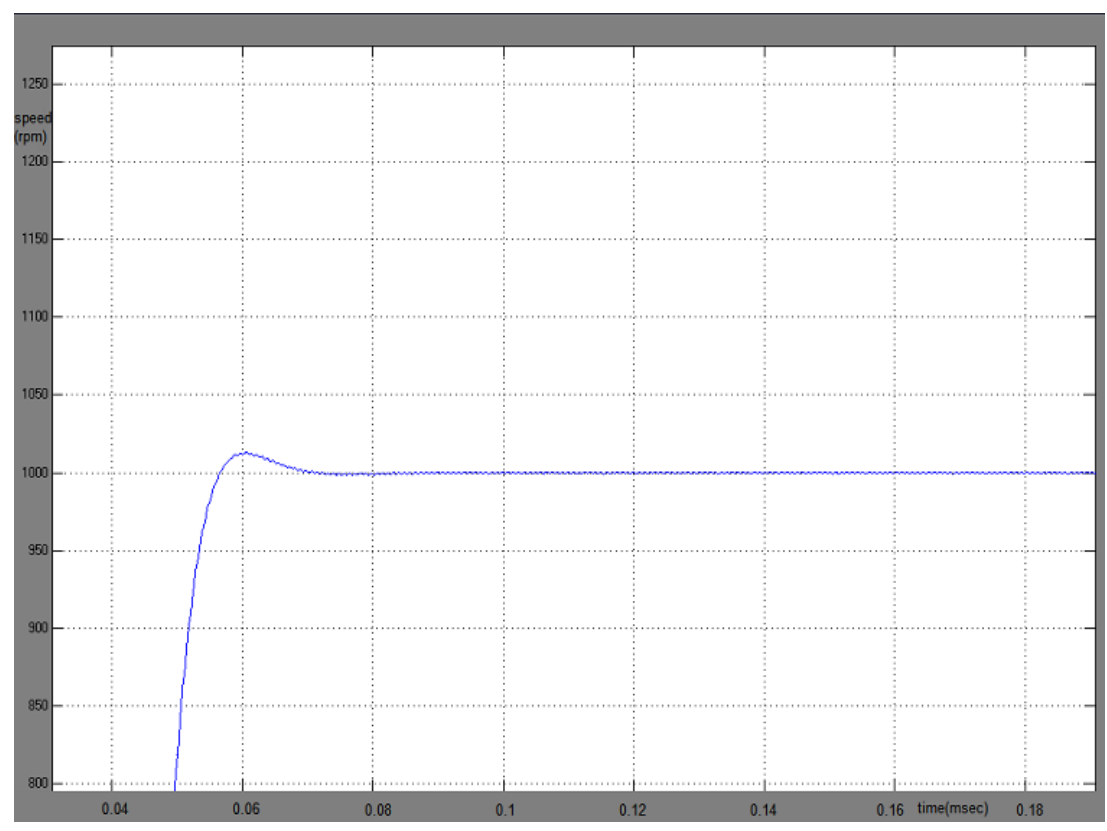

Figure.4.a.GA-PID controller response for sinusoidal Nonlinearity (Speed of DC drive(rpm) Vs time(ms) 


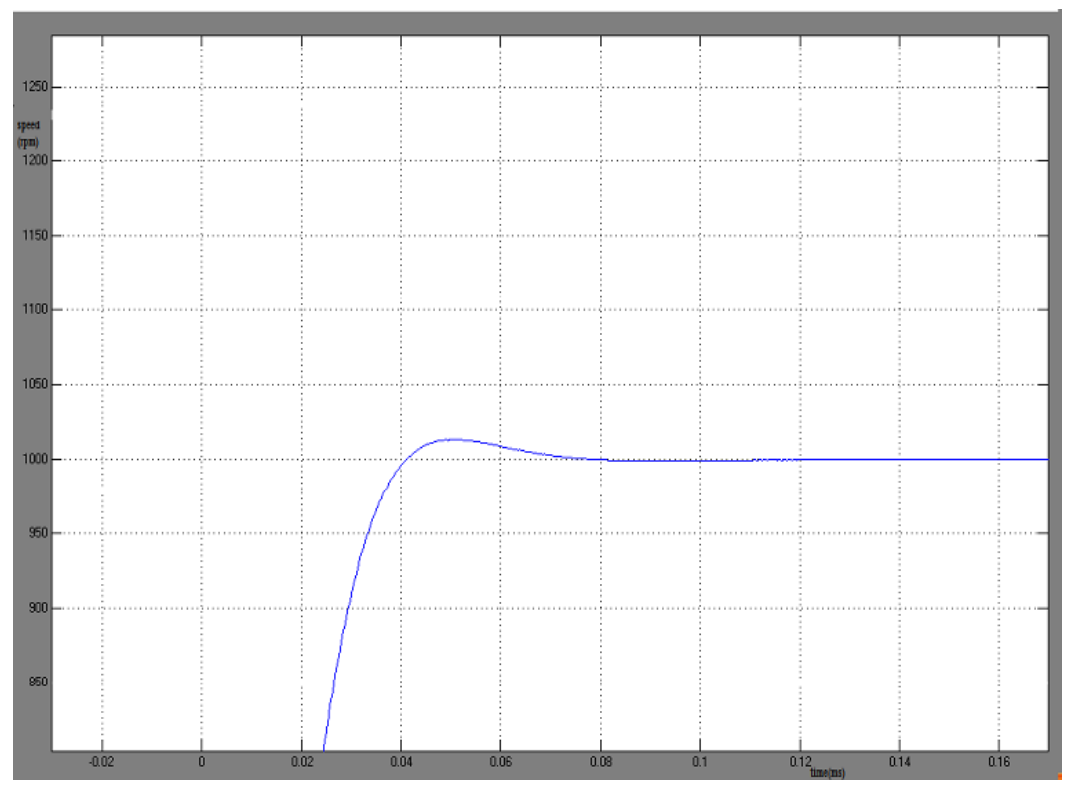

Figure.4.b.GA-PID controller response for Saw tooth Nonlinearity (Speed of DC drive(rpm) Vs time(ms)

The performance of GA-PID controller is carried for any second order drive and it is compared with the conventional controller in MATLAB computer simulation. The suitability of the proposed method has been demonstrated and the speed control of the drive has been obtained under the following nonlinearities. The comparison tables TABLE-III and TABLE-IV for conventional controller, GAPID controller at different nonlinearities are listed.

Table 3 Comparison Table for Sinusoidal Nonlinearity

\begin{tabular}{|c|c|c|c|c|}
\hline Controller & $\begin{array}{r}\text { Steady } \\
\text { state error } \\
(\mathrm{rpm})\end{array}$ & $\begin{array}{r}\text { Steady } \\
\text { state value } \\
(\mathrm{rpm})\end{array}$ & $\begin{array}{l}\text { Settling } \\
\text { time } \\
(\mathrm{msec})\end{array}$ & $\begin{array}{l}\text { Peak over } \\
\text { Shoot } \\
\text { (rpm) }\end{array}$ \\
\hline Conventional controller & 100 & 1050 & Infinite & 1050 \\
\hline GAPID controller & 0.2 & 1002 & 0.08 & 1010 \\
\hline
\end{tabular}

Table 4: Comparison Table of Sawtooth Nonlinearity

\begin{tabular}{|c|c|c|c|c|}
\hline Controller & $\begin{array}{l}\text { Steady state } \\
\text { error } \\
(\mathbf{r p m})\end{array}$ & $\begin{array}{c}\text { Steady } \\
\text { state value } \\
(\mathbf{r p m})\end{array}$ & $\begin{array}{l}\text { Settling time } \\
(\mathbf{m s e c})\end{array}$ & $\begin{array}{l}\text { Peak overshoot } \\
(\mathbf{r p m})\end{array}$ \\
\hline Conventional controller & 50 & 1005 & Infinite & 1095 \\
\hline GAPID controller & 0.1 & 1000 & 0.12 & 1010 \\
\hline
\end{tabular}




\section{Conclusion}

In this paper, Metaherustic algorithm, which is capable of providing good speed regulation with stability along with minimum settling time, steady state error and overshoot (Chin- Hung, 2018), has been proposed and demonstrated for tuning the PID controller. In this paper, initially, the PID Controller has been tuned by the Ziegler Nichols met hod (Akbarzadeh, 2019) which is suitable only for linear process. Then, the same has been adjusted to the optimum values by means of better speed control under various nonlinearities like sinusoidal as well as sawtooth in such a way that the settling time, steady state error and peak overshoot are reduced[3]. Finally, it is evident that the GA-PID controller has provided better performance than the conventional controllers[2].

\section{References}

1. Akbarzadeh M.R , Kim T, Y.T. \& B.Feerouzbakhah,” Evolutionary Fuzzy speed regulation for a DC motor", NASA Center for Autonomous control Engineering.

2. Aroulanandam, V. V., Latchoumi, T. P., Bhavya, B., \& Sultana, S. S. (2019). Object Detection in Convolution Neural Networks Using Iterative Refinements. Revue d'Intelligence Artificielle, 33(5) 367372

3. Chin- Hung wang, Tzung- Pei Hong, and Shian- Shyong Teng," Integrating Fuzzy knowledge by Genetic Algorithms", IEEE Transactions on Evolutionary computation, 2(4).

4. HarionBansal, Shreeraman Ponpathirkoottam," PID controller tuning Techniques", A review, See discussions, stats, and author profiles for this publication at: https://www.researchgate.net/publication/316990192

5. Hong-Gui Han, Lu-MingGe , Jun-FeiQiao, (2018) " An adaptive second order fuzzy neuralnetwork for nonlinear system modeling",Neurocomputing214(2016)837-84.11.Santhosh kumarsumen, Vinod Kumar,

" Speed control of DC motor using optimization Technique" 2nd IEEE International conference on Engineering and technology(ICETECH)

6. Ibtissem Chiha, Noureddine Liouane, and Pierre Borne, (2012)" Research Article Tuning PID Controller Using Multiobjective Ant Colony Optimization", Article in Applied Computational Intelligence and Soft Computing DOI: 10.1155/2012/536326.

7. Latchoumi, T. P., Loganathan, J., Parthiban, L., \& Janakiraman, S. (2016, August). OFS method for selecting active features using clustering techniques. In Proceedings of the International Conference on Informatics and Analytics (pp. 1-4).

8. Latchoumi, T. P., \& Parthiban, L. (2016). Secure Data Storage in Cloud Environment using MAS. Indian Journal of Science and Technology, 9, 24-29.

9. Latchoumi, T. P., \& Kannan, V. V. (2013). Synthetic Identity of Crime Detection. International Journal, 3(7), 124-129.

10. Latchoumi, T. P., Kannan, V. V., \& Ezhilarasi, T. P. (2013). Leasing Processing Power from Mid network using Wireless Communication. International Journal, 3(5), 191-199.

11. Prathibanandhi .K and R Ramesh, (2018)" Hybrid control technique for minimizing the torque ripple of brushless direct current motor", Measurement and Control 51(7-8) 321-335 () The Author(s) 2018 Article reuse guidelines: sagepub.com/journals-permission.

12. Prathibanandhi . K and R Ramesh, (2018) "Hybrid control technique for minimizing the torque ripple of brushless direct current motor", Measurement and Control, 51(7-8) 321-335 @ The Author(s) Article reuse guidelines: sagepub.com/journals-permission.

13. Ranjeeth, S., Latchoumi, T. P., Sivaram, M., Jayanthiladevi, A., \& Kumar, T. S. (2019, December). Predicting Student Performance with ANNQ3H: A Case Study in Secondary Education. In 2019 International Conference on Computational Intelligence and Knowledge Economy (ICCIKE) (pp. 603607). IEEE.

14. Ranjeeth, S., \& Latchoumi, T. P. (2020),Predicting Kids Malnutrition Using Multilayer Perceptron with Stochastic Gradient Descent, 34(5), Revue d'Intelligence Artificielle, 631-636

15. Sekaran, K., Rajakumar, R., Dinesh, K., Rajkumar, Y., Latchoumi, T. P., Kadry, S., \& Lim, S. (2020). An energy-efficient cluster head selection in wireless sensor network using grey wolf optimization algorithm. TELKOMNIKA, 18(6), 2822-2833.

16. Shankar, G., Latchoumi, T. P., Chithambarathanu, M., Balayesu, N., \& Shanmugapriya, C. (2020). An Efficient Survey on Energy Conservation System with Video Surveillance. Journal of Xian University of Architecture and Technology, 12(7), 100-106. 
17. Thirupura Sundari. K, Divya Bharathi S, Grace Priyavarshini R,Tharani. J, (2019) “Tuning PID Controller for a Two Tank Process and Its Parameter Monitoring using IoT”, International Journal of Recent Technology and Engineering (IJRTE) ISSN: 2277-3878, 8(3),

18. Umesh Kumar Bansal, Rakesh Narvey," (2013) Speed control of DC motor by using Fuzzy PID controller” ,Advance in Electronic and Electric Engineering,ISSN2231-1297,3(9), pp1209-1220 Research India Publications.a Ismail and A.M.Sharaf

19. Younis S. Dawood, Ali KMahmood and Muhammed A. Ibrahim, "Comparison of PID, GA and F. uzzy Logic Controllers for Cruise Control System”,International Journal of Computing and Digital Systems, ISSN :(2210-142X) 